\title{
Predominant hosting lead(II) in ternary mixtures of heavy metal ions by a novel of diethylaminomethyl-calix[4]resorcinarene
}

\author{
N. N. M. Yusof $\cdot$ Y. Kikuchi $\cdot$ T. Kobayashi
}

Received: 18 February 2012/Revised: 8 May 2012/Accepted: 23 April 2013/Published online: 17 May 2013

(C) Islamic Azad University (IAU) 2013

\begin{abstract}
Heavy metal ions from single and ternary systems of $\mathrm{Pb}(\mathrm{II}), \mathrm{Cu}(\mathrm{II})$, and $\mathrm{Ni}(\mathrm{II})$ adsorbed by calix[4]resorcinarenes in water-chloroform extraction were studied. Comparison was made of calix[4]resorcinarenes, 2,8,14, 20-tetraundecyl calix[4]resorcinarene-4,6,10,12,16,18,22,24octol, and diethylaminomethyl-calix[4]resorcinarene, 5,11, 17,23-tetra(diethylaminomethyl)-2,8,14,20- tetraundecylcalix[4]resorcinarene-4,6,10,12,16,18,22,24-octol, for predominant extraction of their ions from the ternary mixture of aqueous solution at different $\mathrm{pH}$ in a water layer. The hosting of $\mathrm{Pb}(\mathrm{II})$ by the diethylaminomethyl-calix[4]resorcinarene occurred efficiently at pH 6-7. The hosting of $\mathrm{Pb}(\mathrm{II}), \mathrm{Cu}(\mathrm{II})$, and $\mathrm{Ni}(\mathrm{II})$ ions for the ternary aqueous mixture was applied to the Langmuir isotherm. Adsorption was studied using nuclear magnetic resonance spectroscopy in a water-deuterium chloroform extraction system. Results showed that as the heavy metal ions were included into the host cavity, the observation of shifted peaks of water molecules from downfield to higher field was visible in the nuclear magnetic resonance spectra, meaning that water molecules were included
\end{abstract}

N. N. M. Yusof · T. Kobayashi ( $\square)$

Department of Materials Science and Technology, Nagaoka

University of Technology, 1603-1 Kamitomioka,

Nagaoka, Niigata 940-2188, Japan

e-mail: takaomi@nagaokaut.ac.jp

\section{N. N. M. Yusof}

Section of Chemical Engineering Technology, University of Kuala Lumpur (MICET), Lot 1988 Taboh Naning,

Kawasan Perindustrian Bandar Vendor,

78000 Alor Gajah, Malacca, Malaysia

\section{Y. Kikuchi}

Department of Chemical and Biological Engineering, Hachinohe National College of Technology, 16-1 Uwanotai Tamonaki, Hachinohe-shi, Aomori 0.9-1192, Japan with heavy metal ion into the host cavity. The spectra also showed that the diethylamino group expressed formation of the coordination complex between the diethylaminomethylcalix[4]resorcinarene and $\mathrm{Pb}(\mathrm{II})$ for the purpose of predominant hosting of $\mathrm{Pb}(\mathrm{II})$.

Keywords Calix[4]resorcinarenes - Langmuir isotherm · Nuclear magnetic resonance analysis · Wastewater treatment

\section{Introduction}

Recently, industrial wastewater effluents are often encountered in facilities conducting metal plating and electroplating, or producing fertilizers, batteries, dyes, chemical pharmaceuticals, and electronic devices, where considerable amounts of toxic and pollutant heavy metals are used. Such sites attract attention for development of effluent treatment in several fields. Heavy metals such as lead $(\mathrm{Pb})$, copper $(\mathrm{Cu})$, nickel $(\mathrm{Ni})$, and others are well known to be associated with a tendency to accumulate in living organisms and are known to be highly toxic when absorbed into the human body (Friberg et al. 1979). Generally, the treatment of such industrial waste typically involves expensive techniques such as chemical precipitation, membrane adsorption, ion exchange, and adsorption on activated carbon (Rengaraj et al. 2001; Karthikeyan et al. 2005). Although adsorbents are obtainable at low cost, for example, natural adsorbents such as peanut pellets (Johnson et al. 2002), leaf powder (Ngah and Hanafiah 2008), and organosolv lignin (Acemioglu et al. 2003), active compounds in natural adsorbents are known to be insufficient for treating low levels of heavy metal ions in wastewater. Therefore, new processes including synthetic 
adsorbents must be developed to produce an alternative adsorbent. Especially, high activity of adsorbents is at meeting point of several areas in chemical sciences from the design of recognition and separation process. That is, a technique in the specificity for the recognition of specific analytes has attracted increasing interest in recent years.

Calix[4]resorcinarenes are known to be resorcinol-based macrocyclic or cyclic oligomers that possess a cone-shaped molecular cavity formed by four resorcinol units. These cyclic tetramers are prepared by acid-catalyzed condensation of resorcinol and aldehydes. Consequently, these interesting compounds are capable of forming host-guest complexes. In a pioneering work, Aoyama et al. (1989) demonstrated the potential of calix[4]resorcinarenes as a host-guest complex to interact with other molecules such as organic cations, anions, and molecules. Meanwhile, calix[4]arenes that were initially available for cation transport of $\mathrm{Li}(\mathrm{II}), \mathrm{Na}$ (II), and other cations from group I were investigated by Izatt et al. (1983, 1985). Furthermore, some reports have described the uses of calix[4]resorcinarene as a metal ion extraction agent as a single component of heavy metal ions. Such usefulness of the host, calix[4]resorcinarene, was used in many applications for liquid membranes (Minhas et al. 2010) and as an additive in chemical sensing for HPLC stationary phase and metal ion extraction agents (Jumina Sarjono et al. 2007). These works were focused in uses of only HPLC stationary phase for analytical field. Minhas and his co-workers (2010) studied the selectivity of $\mathrm{Hg}$ (II) as a carrier on the efficiency of transport process in extraction using a bulk liquid membrane containing calix[4]arene. However, the utilization of calix[4]resorcinarenes as an adsorbent in heavy metal ions remains limited. Little is known of details for separation mixtures of heavy metal. Therefore, challenges remain which hinder the study of separation behavior of such calix[4]resorcinarene by hosting the metal ions. In addition, these calix[4]resorcinarene hosts containing longchain alkyl groups in the arene ring increase the solubility in organic solvents. Thus, they are having a potential as an application of additives, for example, used in coating with paint in order to appear heavy metal sorption. There would be possibility to such appearance of absorption specificity in several industrial products by paint and thin active layer formation on the bulk matrix for introducing heavy metal capture.

In the present study, two series of calix[4]resorcinarenes derivatives of 2,8,14,20-tetraundecylcalix[4]resorcinarene4,6,10,12,16,18,22,24-octol (N-host) and 5,11,17,23-tetra (diethylaminomethyl)-2,8,14,20-tetraundecyl calix[4]resorcinarene-4,6,10,12,16,18,22,24-octol (DA-host) (Fig. 1) were synthesized and used as adsorbents for $\mathrm{Pb}(\mathrm{II}), \mathrm{Cu}(\mathrm{II})$, $\mathrm{Ni}(\mathrm{II})$ ions, and their mixtures for uptake in an aqueous medium at different $\mathrm{pH}$. The intention was to investigate the competitive adsorption behavior of the series of the adsorbent in removal of ternary component of $\mathrm{Pb}(\mathrm{II})$, $\mathrm{Cu}(\mathrm{II})$, and $\mathrm{Ni}(\mathrm{II})$ from aqueous solution. The experimental factors such as $\mathrm{pH}$ variation and ion concentration in aqueous solution side for liquid-liquid extraction with chloroform which containing the hosts as adsorbent were reported in this paper. This research was completed during September 2011, at laboratory under Department of Materials Science and Technology of Nagaoka University of Technology, Japan.

\section{Materials and methods}

\section{Materials}

The materials used in this study consisted of resorcinol and dodecanal, which were purchased from Fluka Chemical Co. (Japan). Formaldehyde and diethylamine were purchased from Tokyo Chemical Industry Co. Ltd. (Japan). Benzene, ethanol, and $12 \mathrm{~N}$ hydrochloric acid $(\mathrm{HCl})$ were obtained from Nacalai Tesque Inc. (Japan). All chemicals were used without further purification.

Preparation of 2,8,14,20-

tetraundecylcalix[4]resorcinarene-

$4,6,10,12,16,18,22,24-$ octol (N-host)

The N-host was synthesized by dissolving resorcinol $(25.32 \mathrm{~g}, 0.23 \mathrm{~mol})$ and dodecanal $(42.39 \mathrm{~g}, 0.23 \mathrm{~mol})$ in ethanol $(300 \mathrm{~mL})$. Then, $12 \mathrm{~N} \mathrm{HCl}(50 \mathrm{~mL})$ was added to the mixture of solution at $0{ }^{\circ} \mathrm{C}$. The mixture was stirred and heated to $70{ }^{\circ} \mathrm{C}$ under nitrogen atmosphere for $10 \mathrm{~h}$, after which the precipitates that had separated on cooling the mixture down to room temperature were recovered by filtration. Small amounts of additional precipitates were obtained by addition of water to the filtrate. The precipitates were combined, washed thoroughly with hot water $\left(80{ }^{\circ} \mathrm{C}, 10 \mathrm{~L}\right)$, and then recrystallized twice from methanol and twice from hexane-acetone. Finally, the powders were dried at $0.2 \mathrm{mmHg}$ for $24 \mathrm{~h}$. This process gave the compound as a monohydrate as colorless needles (Faizal et al. 2009). The yield of the N-host was $50.2 \%$. Then, Fourier transform infrared spectroscopy (FT-IR) (IR Prestige-21 FTIR-8400s; Shimadzu Corp., Japan) and nuclear magnetic resonance spectroscopy (NMR) (JNM GX400; JEOL, Japan) were used to characterize the N-host. The FT-IR of the $\mathrm{N}$-host in potassium bromide $(\mathrm{KBr})$ method was 


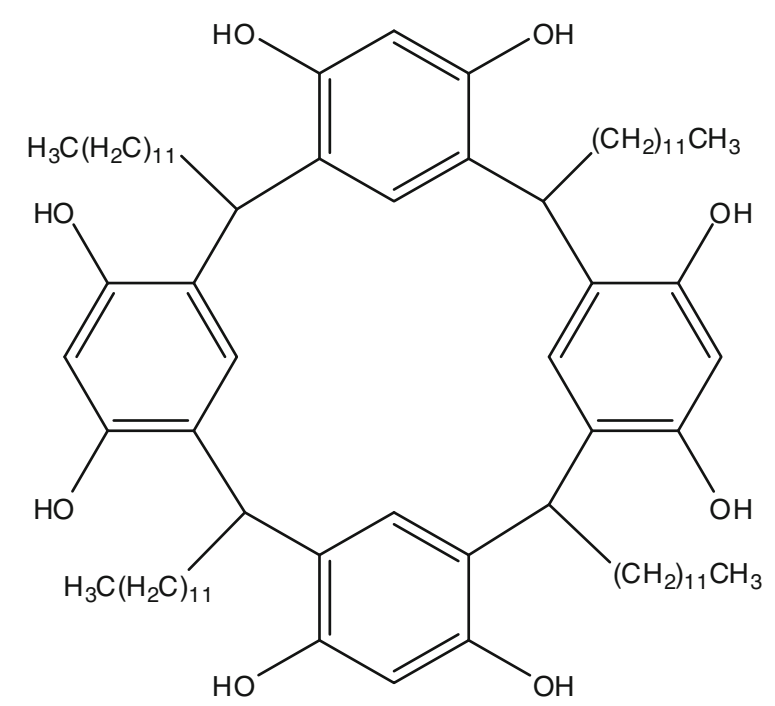

(a) 2,8,14,20-tetraundecylcalix[4]resorcinarene-4,6,10,12,16,18,22,24-octol

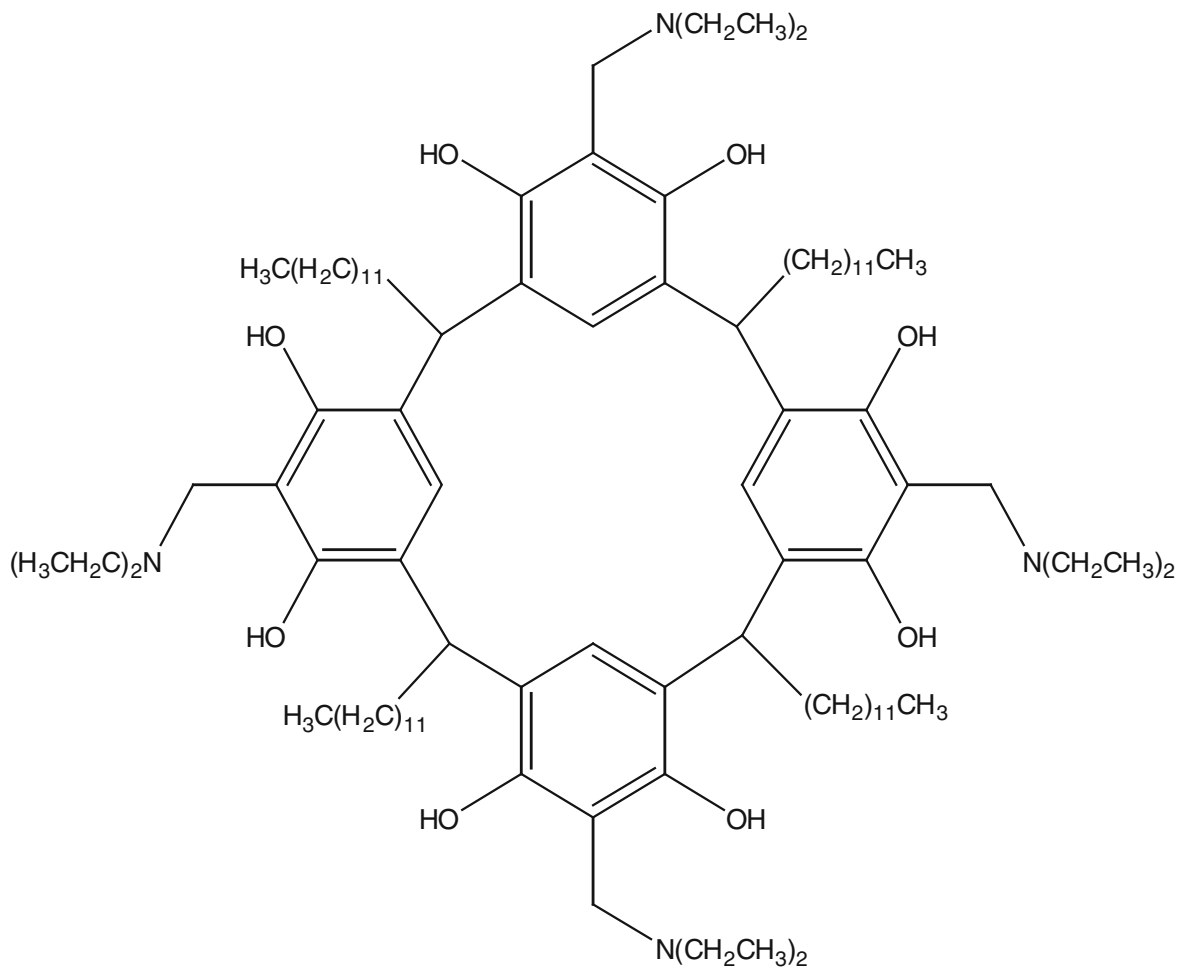

(b) 5,11,17,23-tetra(diethylaminomethyl)-2,8,14,20-

tetraundecylcalix[4]resorcinarene-4,6,10,12,16,18,22,24-octol

Fig. 1 Chemical structure of calix[4]resorcinarenes. a 2,8,14,20-tetraundecylcalix[4]resorcinarene-4,6,10,12,16,18,22,24-octol. b 5,11,17,23tetra(diethylaminomethyl)-2,8,14,20-tetraundecylcalix[4]resorcinarene-4,6,10,12,16,18,22,24-octol

applied $\left[\mathrm{cm}^{-1}\right]: 3,469(\mathrm{O}-\mathrm{H}), 2,900(-\mathrm{C}-\mathrm{H}$ stretching), $1,616-1,496$, and $837-719$ (benzene ring of the N-host). ${ }^{1} \mathrm{H}-\mathrm{NMR}$ of the N-host: in deuterium chloroform $\left(\mathrm{CDCl}_{3}\right)$ $\delta[\mathrm{ppm}]=9.68-9.32(m, \mathrm{OH}), 7.29-6.14\left(s, \mathrm{H}_{1}\right.$ and $\left.\mathrm{H}_{2}\right)$, $4.60-4.33(s, \mathrm{OH}), 141-1.30\left(m, 25 \mathrm{H}, \mathrm{CH}_{2}\right), 0.93-0.90(m$, $\left.4 \mathrm{H}, \mathrm{CH}_{3}\right)$. 
Preparation of 5,11,17,23-tetra(diethylaminomethyl)2,8,14,20-tetraundecyl calix[4]resorcinarene4,6,10,12,16,18,22,24-octol (DA-host)

To a mixture of $10.0 \mathrm{~g}$ of the N-host $(0.045 \mathrm{~mol}), 7.21 \mathrm{~g}$ of formaldehyde $(0.12 \mathrm{~mol})$ and $6.51 \mathrm{~g}$ of diethylamine $(0.045 \mathrm{~mol})$ were added to $1: 1 \%(\mathrm{v} / \mathrm{v})$ benzene-ethanol solution for $100 \mathrm{~mL}$. The mixture was kept under nitrogen atmosphere for $24 \mathrm{~h}$ at room temperature. Then, the mixture was heated for $120 \mathrm{~min}$ at $60{ }^{\circ} \mathrm{C}$. The mixture of solution was cooled and then evaporated to obtain a viscous solution. The viscous solution was continued with recrystallization using a mixture of $1: 1 \%(\mathrm{v} / \mathrm{v})$ benzeneethanol solution until a white precipitate was obtained (Knyazeva et al. 2009). The DA-host was dried in vacuum $(0.2 \mathrm{mmHg})$ to obtain a constant mass and was then characterized using (IR Prestige-21 FTIR-8400s; Shimadzu Corp., Japan) and NMR (JNM GX400; JEOL, Japan). The yield of the DA-host was $76.2 \%$. FT-IR of the DA-host using the $\mathrm{KBr}$ method was used $\left[\mathrm{cm}^{-1}\right]$ : 3,277 $(\mathrm{O}-\mathrm{H})$, 2,916-2,848 (-C-H stretching), 1,577-1,475 (benzene ring of the DA-host), 1,355-1,244, and 981-777 (-CH-N$\left.\left(\mathrm{CH}_{2} \mathrm{CH}_{3}\right)_{2}\right) .{ }^{1} \mathrm{H}-\mathrm{NMR}$ of the DA-host: $\left(\mathrm{CDCl}_{3}\right) \delta$ $[\mathrm{ppm}]=3.87-3.72(\mathrm{~m}, \mathrm{OH}), 7.09\left(s, \mathrm{H}_{3}\right), 4.29-4.25(m$, $\left.\mathrm{CH}_{2}\right), 2.18\left(s, 3 \mathrm{H}, \mathrm{CH}_{2}\right), 1.35-1.25\left(m, 20 \mathrm{H}, \mathrm{CH}_{2}\right), 1.06$ (s, $\left.6 \mathrm{H}, \mathrm{CH}_{3}\right)$.

Adsorption experiments for single and ternary components of heavy metal ions in liquid-liquid extraction

The removal efficiency of single and ternary components of heavy metal ions was investigated. Standard solutions of $\mathrm{Pb}(\mathrm{II}), \mathrm{Cu}(\mathrm{II})$, and $\mathrm{Ni}(\mathrm{II})$ were prepared with appropriate concentrations using analytical reagent grades of each metal purchased from Nacalai Tesque Inc. (Japan). Experiments were performed with liquid-liquid extraction of the water-chloroform system by dissolving $0.2 \mathrm{~g}$ of the hosts to $5 \mathrm{~mL}$ chloroform. Then, $20 \mathrm{~mL}$ of each metal ion $(10 \mathrm{mmol} / \mathrm{L})$ was poured into a different centrifuge tube. The effects of $\mathrm{Pb}(\mathrm{II}), \mathrm{Cu}(\mathrm{II})$, and $\mathrm{Ni}(\mathrm{II})$ adsorption were studied at different $\mathrm{pH}$. The mixture solution $\mathrm{pH}$ was adjusted to the necessary $\mathrm{pH}$ value by adding either $0.1 \mathrm{M}$ sodium hydroxide $(\mathrm{NaOH})$ or $1.0 \mathrm{M}$ hydrochloric acid $(\mathrm{HCl})$. The mixture was mixed well in centrifugation for $60 \mathrm{~min}$ with $600 \mathrm{rpm}$ at different $\mathrm{pH}$. The temperature was controlled to $20^{\circ} \mathrm{C}$. After $60 \mathrm{~min}$, the aqueous solution was separated from the organic layer (chloroform phase). The concentrations of remaining heavy metal ions $\mathrm{Pb}(\mathrm{II})$, $\mathrm{Cu}$ (II), and $\mathrm{Ni}$ (II) in the aqueous solution were measured at a certain wavelength using an atomic adsorption spectrophotometer (AA-6300; Shimadzu Corp., Japan). Optimum conditions for adsorption equilibrium for the N-host and
DA-host onto each metal were found to be $60 \mathrm{~min}$ at $\mathrm{pH} 6$. Selectivity of the N-host and DA-host for the interfering metal ion was evaluated using the following equation (Castillo et al. 2005).

Adsorption capacity, $q_{\mathrm{e}}=\frac{\left(C_{\mathrm{i}}-C_{\mathrm{f}}\right)}{W} V$

Therein, $C_{\mathrm{i}}$ signifies the initial concentration of metal ion $(\mathrm{mmol} / \mathrm{L})$ and $C_{\mathrm{f}}$ denotes the final concentration of metal ion $(\mathrm{mmol} / \mathrm{L})$ after equilibrium, $V$ represents the volume of the metal ion solution (L), and $W$ stands for the weight of the N-host or DA-host (g) used. The unit for the adsorption capacity $q_{\mathrm{e}}$ was $\mathrm{mmol} / \mathrm{g}$.

The adsorption experiment for the DA-host in ternary heavy metal ion solution was conducted in a similar manner to the N-host cases. For the ternary heavy metal ion solution, the concentration was fixed at $10 \mathrm{mmol} / \mathrm{L}$ of each $\mathrm{Pb}$ (II), $\mathrm{Cu}$ (II), and $\mathrm{Ni}$ (II) ion. The purpose was to study the comparison of adsorption capability of heavy metal ions by the N-host and DA-host in the ternary aqueous solution at different $\mathrm{pH}$. Moreover, isotherm studies were conducted at a constant dosage weight $(0.2 \mathrm{~g})$ and by varying the concentration of heavy metal ions within the $10-50 \mathrm{mmol} / \mathrm{L}$ range. The amounts of heavy metal ion adsorption were calculated based on the difference of the heavy metal ions concentrations in aqueous solution before and after adsorption, the volume of the aqueous solution $(20 \mathrm{~mL})$ and the weight of the adsorbent $(0.2 \mathrm{~g})$ using adsorption capacity Eq. (1).

The interaction between the hosts and the heavy metal ions was investigated, and the binding properties were analyzed using NMR spectroscopy (AL-400; JEOL) in a water- $\mathrm{CDCl}_{3}$ system for metal ions. The solid N-host or DA-host $(0.08 \mathrm{~g})$ was diluted in $2.0 \mathrm{~mL} \mathrm{CDCl}_{3}$ in a centrifuge tube $(20 \mathrm{~mL}$ volume), and about $4.0 \mathrm{~mL}$ of heavy metal solution $(100 \mathrm{ppm})$ was poured in the same centrifuge tube. They were mixed well in the centrifuge for $60 \mathrm{~min}$ at $600 \mathrm{rpm}$.

\section{Results and discussion}

Selectivity and characterization of heavy metal ions

In the present work for the calix[4]resorcinarenes, both of the hosts consist the undecyl groups in the arene ring which could increase the solubility in organic solvents. The solubility of the obtained DA-host and N-host in number of organic solvents was evaluated. Both of the hosts were well soluble in tetrahydrofuran, toluene, dichloromethane, benzene, pyridine, $N, N$-dimethylformamide, and $N$-methyl2-pyrrolidone; however, DA-host and N-host were insoluble in water, ethanol, hexane, and dimethyl sulfoxide. In 
addition, the present of DA-host consist four diethylamino groups in the ring, which is the weak base, and it would respond to the $\mathrm{pH}$ based on the equilibrium equation by diethylamino groups as follows:

$-\mathrm{N}\left(\mathrm{C}_{2} \mathrm{H}_{5}\right)_{2} \stackrel{\mathrm{H}^{+}}{\rightleftharpoons}-\stackrel{+}{\mathrm{N}}\left(\mathrm{C}_{2} \mathrm{H}_{5}\right)_{2} \mathrm{H}$

Generally, the $\mathrm{pH}$ of solution can affect the adsorption capacity of many adsorbents (Osu Charles and Odoemelam 2010). Therefore, the $\mathrm{pH}$ measurement was important in the present study to identify a suitable $\mathrm{pH}$ for the adsorption for each heavy metal ion because metal precipitation can occur at high $\mathrm{pH}$ to form insoluble hydroxide compounds, which would interfere with the adsorption experiments. Figure 2 shows the adsorption capacity of $\mathrm{Pb}(\mathrm{II}), \mathrm{Cu}(\mathrm{II})$, or $\mathrm{Ni}$ (II) on the DA-host and $\mathrm{N}$-host. Here, the single component of aqueous heavy metal ion was present in the organic chloroform layer. In liquid-liquid extraction, free species of heavy metal ions were present in acidic solutions of $\mathrm{pH} 2-5$. Relative to the low $\mathrm{pH}$, the adsorptions at higher $\mathrm{pH}$ were found to be enhanced. At $\mathrm{pH}$ higher than 8.0, the precipitate occurred as a formation of a high concentration of hydroxide heavy metal ions leaching ion precipitation. Therefore, additional experiments were performed at $\mathrm{pH} 2-7$ to confirm that the three metals were present in dissolved form. As Fig. 2b shows, the adsorption capacity of $\mathrm{Pb}$ (II) was higher than that of $\mathrm{Cu}(\mathrm{II})$ or $\mathrm{Ni}(\mathrm{II})$, especially for the DA-host in the higher $\mathrm{pH}$ region. The adsorption capacities of $\mathrm{Pb}(\mathrm{II})$ ion were 1.79 and $1.58 \mathrm{mmol} / \mathrm{g}$ for the DA-host and N-host, respectively.

The competitive extractions of $\mathrm{Pb}(\mathrm{II}), \mathrm{Cu}(\mathrm{II})$, and $\mathrm{Ni}(\mathrm{II})$ were further studied for a ternary mixture containing $10 \mathrm{mmol} / \mathrm{L}$ concentrations to investigate the separation of heavy metal ions. Thus, Fig. 3 presents the adsorption capacity of each component heavy metal ion at several levels of $\mathrm{pH}$. The competitive adsorptions of the ternary

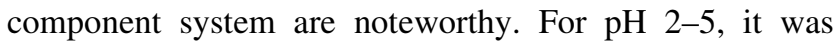
observed that the competitive adsorption behaviors of $\mathrm{Cu}(\mathrm{II})$ and $\mathrm{Ni}$ (II) ions showed their adsorption less than $0.15 \mathrm{mmol} / \mathrm{g}$. At $\mathrm{pH} 5$, the $\mathrm{Pb}$ (II) ion bound with $0.3-0.4 \mathrm{mmol} / \mathrm{g}$ for both hosts. At $\mathrm{pH} 6-7$, the value of adsorption capacity was increased in both hosts. For example, the $\mathrm{Pb}$ (II) ion was adsorbed, respectively, with 1.06 and $0.89 \mathrm{mmol} / \mathrm{g}$ for the DA-host and N-host. However, comparison between single and ternary components indicated that the adsorption of $\mathrm{Pb}$ (II) was inhibited slightly by the presence of $\mathrm{Cu}(\mathrm{II})$ and $\mathrm{Ni}(\mathrm{II})$ ions, which indicates strongly that competitive adsorption occurred in the ternary component systems for both adsorbents.

Slight differences were apparent in the adsorption behaviors of the N-host and DA-host. Data of the ternary component confirmed that the adsorption capacity of the
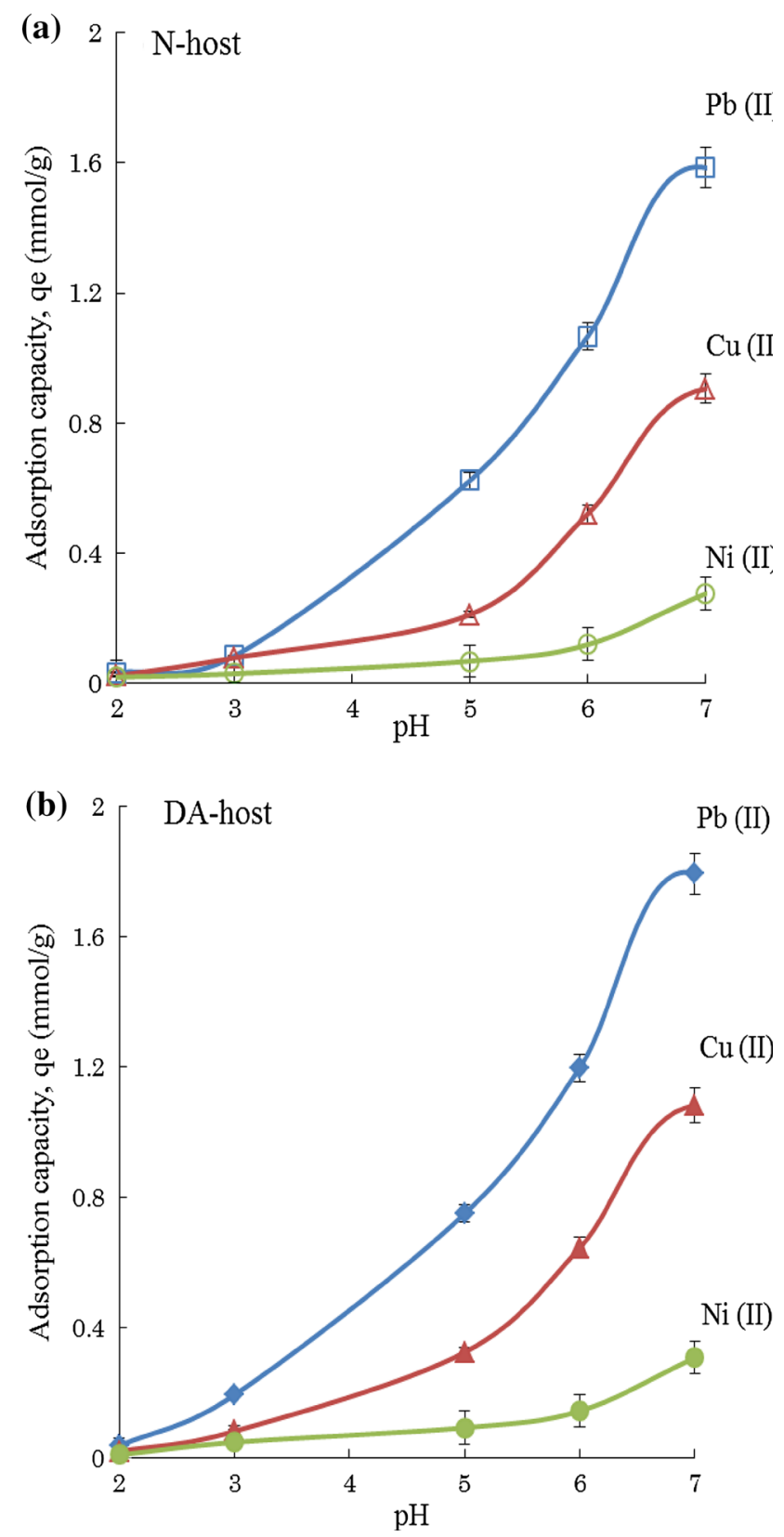

Fig. 2 Effect of $\mathrm{pH}$ on the adsorption capacity of single-component heavy metal ions onto a N-host and b DA-host [Initial concentration of each heavy metal $=10 \mathrm{mmol} / \mathrm{L}$; Volume $=20 \mathrm{~mL}$; Dosage of the hosts $=0.2 \mathrm{~g}$; Agitation period $=60 \mathrm{~min}]$

DA-host became higher than that of the N-host. The diethylamino groups were present on the DA-host, showing a positively changed group at lower $\mathrm{pH}$. Therefore, these phenomena agreed well with the fact that the host expressed electrostatic repulsion against the metal ions. However, the DA-host showed good potential for heavy metal adsorption at $\mathrm{pH} 6-7$. At $\mathrm{pH} 7$, the adsorption capacities were 1.06 and $0.89 \mathrm{mmol} / \mathrm{g}$, respectively, for the DA-host and N-host, indicating that the calix[4]resorcinarene frame can fit with 

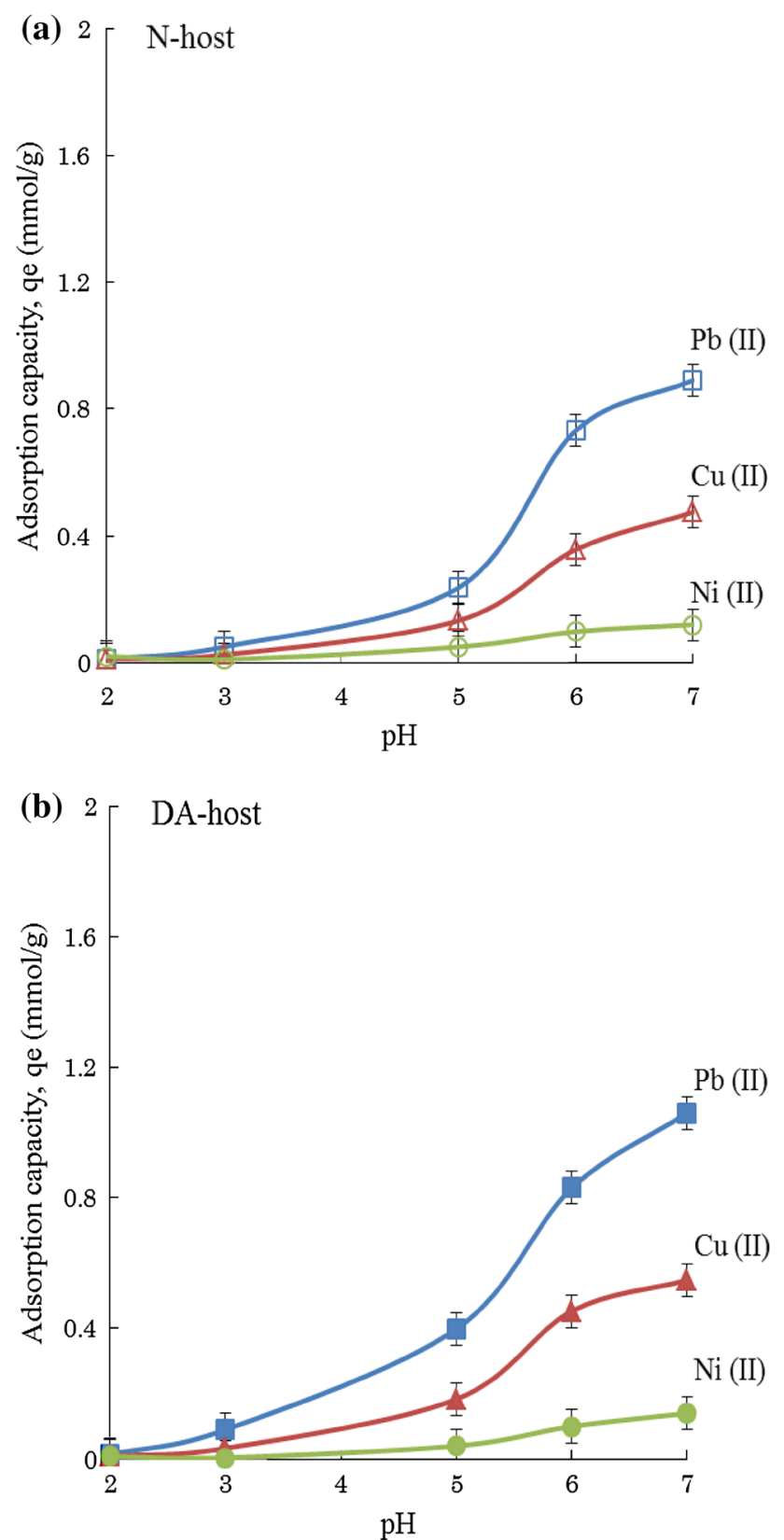

Fig. 3 Effect of $\mathrm{pH}$ on the adsorption capacity of each ion in ternary component heavy metal ions onto a N-host and b DA-host [Initial concentration of each heavy metal $=10 \mathrm{mmol} / \mathrm{L}$; Volume $=20 \mathrm{~mL}$; Dosage of the hosts $=0.2 \mathrm{~g}$; Agitation period $=60 \mathrm{~min}]$

such a $\mathrm{Pb}$ (II) ion because less electrostatic repulsion was present at this $\mathrm{pH}$ for the DA-host. In addition, the higher capability of the DA-host was presumed to be attributable to the presence of coordination of diethylamino groups to the ions. Consequently, the adsorption capacity of $\mathrm{Pb}(\mathrm{II})$ in ternary components of heavy metal ions was found in both hosts to be a tendency for high adsorption capacity to others.

The adsorption behavior of the heavy metal ions on the DA-host and N-hosts was analyzed by using NMR spectroscopy in water- $\mathrm{CDCl}_{3}$ containing $10 \mathrm{mmol} / \mathrm{L}$ concentrations of respective heavy metals. Figure $4 a$ and $b$ present a comparison of the ${ }^{1} \mathrm{H}-\mathrm{NMR}$ spectra of the N-host and DA-host as measured at room temperature in $\mathrm{CDCl}_{3}$ for each extraction experiment. Figure $4 \mathrm{a}$ shows that the signals at 7.21 and $6.10 \mathrm{ppm}$ were indicated, respectively, in outer and inner aromatic protons in the host ring for $\mathrm{H}_{1}$ and $\mathrm{H}_{2}$. In spectrum $\mathrm{A}$ for the N-host, the singlet peak intensity of the $\mathrm{H}_{2}$ protons was weakened and the outer proton peak at $6.10 \mathrm{ppm}$ was enhanced in $\mathrm{Pb}$ (II) extraction. The $\mathrm{OH}$ proton appeared as multiplet peaks of equal intensities centered at 9.58 and $9.26 \mathrm{ppm}$. However, the $\mathrm{N}$-host expressed a lower magnetic shift, meaning that the leaving metal inclusion unshielded with the inner ring current effect of the calix[4]resorcinarene. It is noteworthy that the peak of water, which was present in the N-host, appeared at $4.68 \mathrm{ppm}$ and showed a higher chemical shift at $4.07 \mathrm{ppm}$ for $\mathrm{Pb}$ (II) systems. Results show that water coordinated to the $\mathrm{OH}$ group of the $\mathrm{N}$-host when the $\mathrm{Pb}$ (II) ion was included. The signals at 1.41 and $0.90 \mathrm{ppm}$ corresponded to the alkyl hydrophobic region for the resorcinol units. In panel (a), spectrum A shows one molecule of water, suggesting that this was assigned at $4.68 \mathrm{ppm}$ for the crystalline N-host (Ma et al. 2001). For spectrum B, the water molecule peak appeared in a higher field at $3.49 \mathrm{ppm}$ when the N-host in $\mathrm{CDCl}_{3}$ was washed with water. This shift indicates that water was included in the inner arene cone. However, when $\mathrm{Pb}$ (II) ion was present in the water layer, the water peak shifted forward to the lower field at $4.07 \mathrm{ppm}$, which strongly suggests that the water molecule supported the $\mathrm{Pb}$ (II) ion hosting to the inner N-host.

However, in Fig. $4 \mathrm{~b}$ for the DA-host with diethylamino groups, protons from $\mathrm{CH}_{2}$ and $\mathrm{CH}_{3}$ were observed, respectively, at $3.72-3.78 \mathrm{ppm}$ and $1.06 \mathrm{ppm}$. The water was present, showing its signal at $2.57 \mathrm{ppm}$. The broad $\mathrm{OH}$ signal was shown in the lower field at $8.25 \mathrm{ppm}$ for the spectrum $\mathrm{B}$ when the water layer contained $\mathrm{Pb}$ (II) ion with $10 \mathrm{ppm}$ concentration. In addition, the $\mathrm{OH}$ signal was shifted to about $8.80 \mathrm{ppm}$. The downfield shift indicated that the $\mathrm{OH}$ groups positioned on the aryl ring were directed outward when the metal ion was included. Additionally, it was noted that the signal splitting of the multiplet for the $\mathrm{CH}_{2}$ group of diethylamino group on the DAhost was changed to a singlet peak when the metal ion for $\mathrm{Pb}$ (II) and $\mathrm{Cu}(\mathrm{II})$ was included in the cone. The significance meant that such metal ion coordinated with the nitrogen atom of the diethylamino group. Consequently, the neighboring $\mathrm{CH}_{2}$ group of the nitrogen atom, which was coordinated, was influenced strongly by the effect of the heavy metal ion. Results of NMR analysis revealed that the heavy metal ion was included in the host cavity through the aid of water molecules in the N-host and also through interaction with the $\mathrm{OH}$ group of the DA-host. 
Fig. 4 Comparison of ${ }^{1} \mathrm{H}-\mathrm{NMR}$ spectra of a N-host and b DAhost for water- $\mathrm{CDCl}_{3}$

extraction. Here, $\mathrm{CDCl}_{3}$ was used as organic solvent and water layer contained $10 \mathrm{ppm}$ metal ions. Spectra $A, B, C, D$, and $E$ were for crystalline samples, washing the hosts in $\mathrm{CDCl}_{3}$ by water, $\mathrm{Pb}(\mathrm{II}), \mathrm{Cu}(\mathrm{II})$, and $\mathrm{Ni}(\mathrm{II})$ aqueous solution with the $10 \mathrm{ppm}$ concentration

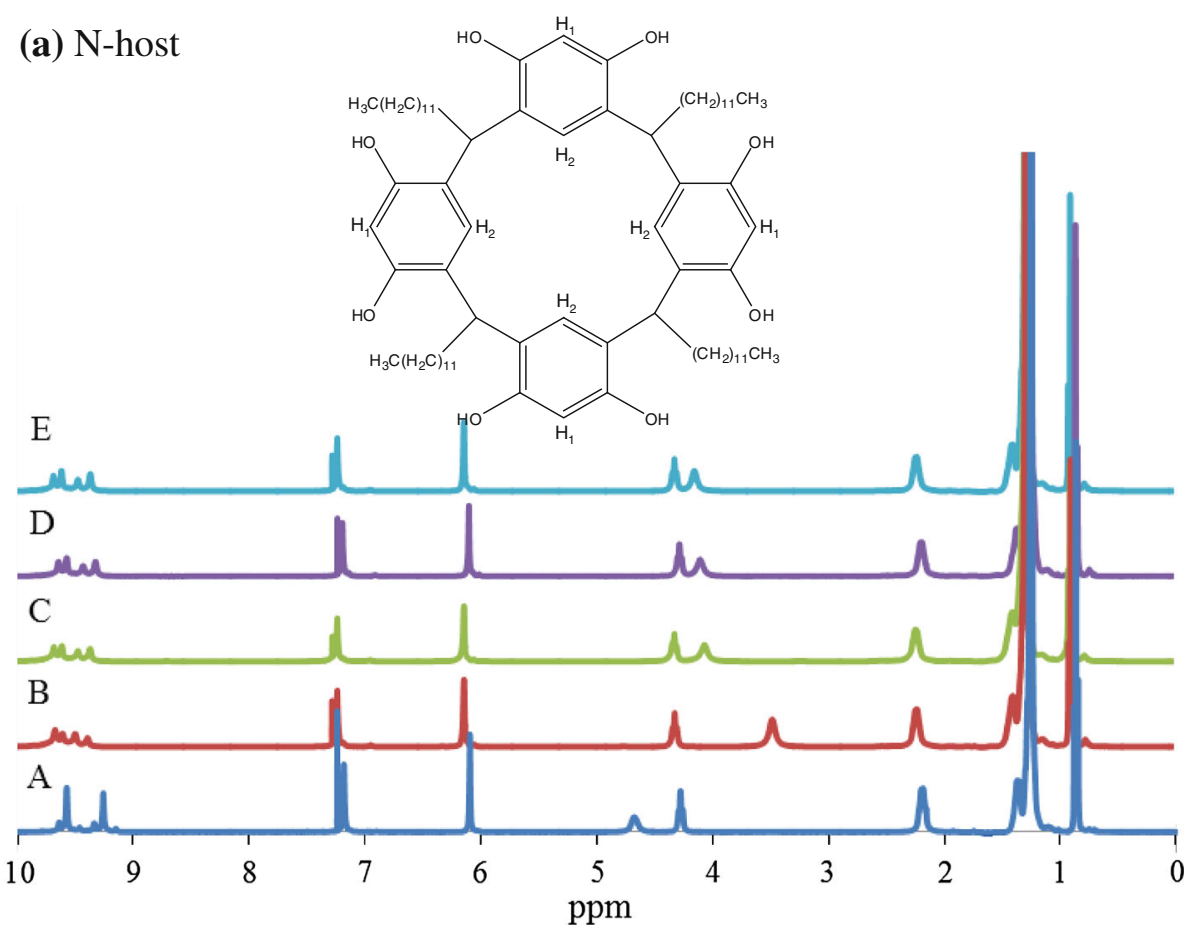

(b) DA-host

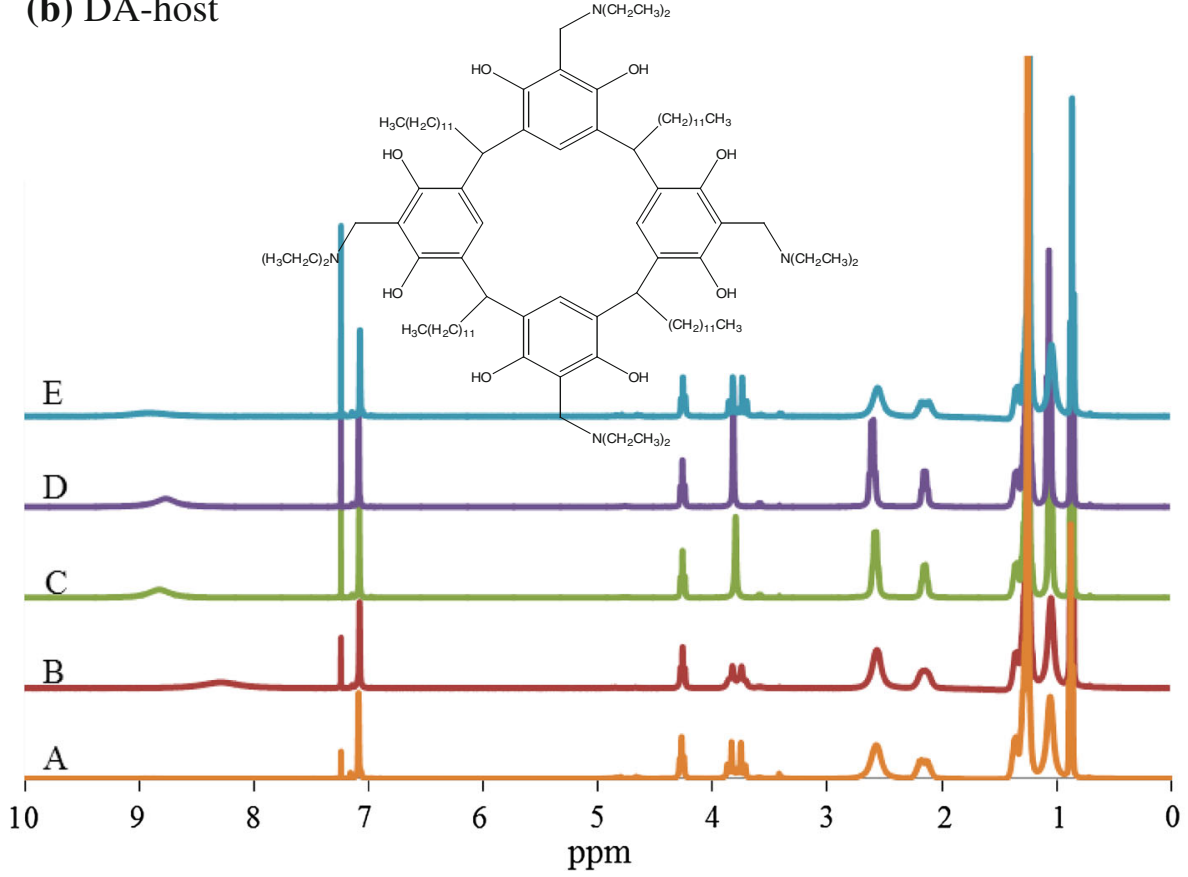

\section{Adsorption isotherms}

Adsorption isotherms are known to be fundamental in describing the adsorption behavior of adsorbate ions. Therefore, analyses of $\mathrm{Pb}(\mathrm{II}), \mathrm{Cu}$ (II), and $\mathrm{Ni}(\mathrm{II})$ with the $\mathrm{N}$-host and DA-host were conducted for two phases applied in Langmuir equilibrium isotherms (Panida and Pisit 2010). To inform the adsorption isotherms of the calix[4]resorcinarene host and the ion guest, the relation between the concentration of the ion adsorbate in the aqueous solution and the amount of ion adsorbed onto the adsorbent was examined using the Langmuir equation.

$\frac{C_{\mathrm{e}}}{Q_{\mathrm{e}}}=\frac{C_{\mathrm{e}}}{Q_{\mathrm{m}}}+\frac{1}{Q_{\mathrm{m}} b}$ 
In that equation, $Q_{\mathrm{m}}$ signifies the maximum amount of hosting capacity of heavy metal ions adsorbed for a complete monolayer $(\mathrm{mmol} / \mathrm{g}), \quad C_{\mathrm{e}}$ represents the equilibrium concentration of heavy metal ions $(\mathrm{mmol} / \mathrm{L})$, $Q_{\mathrm{e}}$ denotes the amount of heavy metal ions adsorbed at the equilibrium concentration ( $\mathrm{mmol} / \mathrm{g}$ ), and $b$ stands for the Langmuir constant related to the affinity of the binding sites $(\mathrm{L} / \mathrm{mmol})$. Figure 5 shows the equilibrium adsorption isotherms of $\mathrm{Pb}(\mathrm{II}), \mathrm{Cu}(\mathrm{II})$, and $\mathrm{Ni}(\mathrm{II})$ onto the N-host and DA-host as a function of the initial concentration among heavy metals. The calculated results of Langmuir isotherm constants are presented in Table 1 . The experimental data show that the maximum adsorption capacity for hosting each heavy metal was obtained. The data revealed that the adsorption capacity of heavy metal ions onto DA-host was higher than the adsorption capacity of heavy metal ions onto the N-host. These assignments might be explained by the differences of their chemical structures of the N-host and DA-host. The adsorbent of the DA-host contained additional diethylamino groups, which might be responsible for the effectiveness of hosting sites of heavy metal ions through coordination interaction with nitrogen atom and metal ions. However, the N-host contained only hydroxyl groups for the capture of metal ions. Therefore, the analytical results showed that the DA-host expressed a great amount of hosting capacity $Q_{m}$ and equilibrium constant $b$ for $\mathrm{Pb}(\mathrm{II})$ adsorption.

Langmuir isotherms showed that the adsorption capacity of $\mathrm{Pb}$ (II) was higher than those of $\mathrm{Cu}$ (II) and $\mathrm{Ni}$ (II) for both adsorbents. The respective values of adsorption capacity of $\mathrm{Pb}$ (II), $\mathrm{Cu}(\mathrm{II})$, and $\mathrm{Ni}(\mathrm{II})$ with the concentration $10 \mathrm{ppm}$ were $5.75,3.79$, and $1.15 \mathrm{mmol} / \mathrm{g}$ for the N-host, although those for the DA-host were 6.10, 3.63, and $4.48 \mathrm{mmol} / \mathrm{g}$. Results show that $\mathrm{Pb}(\mathrm{II})$ adsorption by the N-host and DAhost became higher values than those of other metals. Furthermore, the adsorption of $\mathrm{Pb}(\mathrm{II})$ by the DA-host showed higher adsorption than that of the N-host. Here, NMR data suggest that both hosts were cone configurations of calix[4]resorcinarenes (Gutsche 1989). Consequently, these phenomena might be explained in terms of the size of the studied heavy metal ions. For heavy metal ions in this study, the size order is shown below.

$\mathrm{Pb}^{2+}(1.19 \AA)>\mathrm{Cu}^{2+}(0.73 \AA)>\mathrm{Ni}^{2+}(0.69 \AA)$

Regarding comparison of the ion diameter and host cavity size, $\mathrm{Pb}$ (II) had ion diameter of $1.19 \AA$. The cavity size of calix[4]resorcinarene was $2.59 \AA$ (Gutsche 1989), although the respective ion diameters of $\mathrm{Cu}(\mathrm{II})$ and $\mathrm{Ni}$ (II) were 0.73 and $0.69 \AA$. Therefore, $\mathrm{Pb}$ (II) was the right choice to fix into the cone shape of the N-host and DAhost, in contrast to $\mathrm{Cu}$ (II) and $\mathrm{Ni}(\mathrm{II})$ (Jain and Kanaiya 2011; Turshatov et al. 2004).
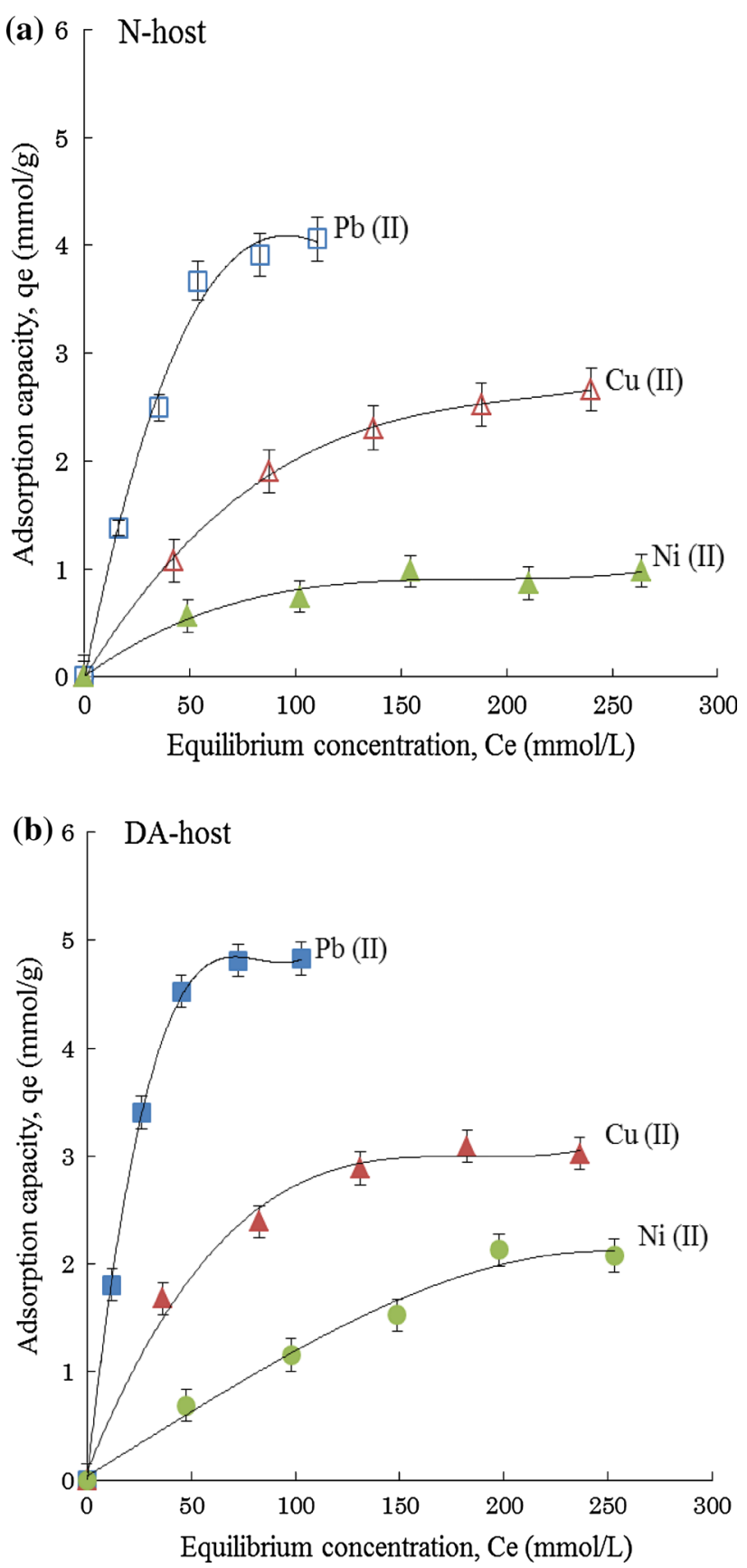

Fig. 5 Comparison of equilibrium adsorption of heavy metal ions from aqueous solution using a N-host and b DA-host [Initial $\mathrm{Pb}(\mathrm{II})$, $\mathrm{Cu}(\mathrm{II})$, and $\mathrm{Ni}(\mathrm{II})$ concentration $=10-50 \mathrm{mmol} / \mathrm{L}$; Volume $=$ $20 \mathrm{~mL}$; Dosage of N-host and DA-host $=0.2 \mathrm{~g} ; \mathrm{pH}=6$; Agitation $=600 \mathrm{rpm}]$

Among the three metal ions, the adsorbents of the $\mathrm{N}$-host and DA-host exhibited the lowest adsorption efficiency for $\mathrm{Ni}(\mathrm{II})$. Results of the Langmuir isotherm underscored that both hosts showed a low adsorption capacity for $\mathrm{Ni}(\mathrm{II})$ adsorbent, perhaps because $\mathrm{Ni}(\mathrm{II})$ is somewhat smaller than the host cone. 
Table 1 Langmuir isotherms with constant and correlation coefficient for the adsorption of $\mathrm{Pb}(\mathrm{II}), \mathrm{Cu}$ (II), and $\mathrm{Ni}$ (II) onto the hosts

\begin{tabular}{lllll}
\hline Adsorbent & Heavy metal & Langmuir & & \\
\cline { 3 - 5 } & & $Q_{\mathrm{m}}(\mathrm{mmol} / \mathrm{g})$ & $b(\mathrm{~L} / \mathrm{mmol})$ & $R^{2}$ \\
\hline N-host & $\mathrm{Pb}(\mathrm{II})$ & 5.75 & 0.02 & 0.96 \\
& $\mathrm{Cu}(\mathrm{II})$ & 3.79 & 0.01 & 0.99 \\
& $\mathrm{Ni}(\mathrm{II})$ & 1.15 & 0 & 0.97 \\
DA-host & $\mathrm{Pb}(\mathrm{II})$ & 6.1 & 0.04 & 0.98 \\
& $\mathrm{Cu}(\mathrm{II})$ & 3.63 & 0.03 & 0.99 \\
& $\mathrm{Ni}(\mathrm{II})$ & 4.48 & 0.02 & 0.88 \\
\hline
\end{tabular}

Langmuir isotherm constant are presented in Table 1 and shows the maximum adsorption capacity, $Q_{\mathrm{m}}$ for hosting each heavy metal

$Q_{m}$ maximum amount of adsorption, $b$ Langmuir constant, $R^{2}$ correlation coefficient

\section{Conclusion}

In the present study, the capacities of the N-host and DAhost to adsorb $\mathrm{Pb}(\mathrm{II}), \mathrm{Cu}(\mathrm{II})$, and $\mathrm{Ni}$ (II) ions from aqueous solutions were examined by separation experiment of $\mathrm{Pb}(\mathrm{II}), \mathrm{Cu}$ (II), and $\mathrm{Ni}(\mathrm{II})$ at different $\mathrm{pH}$. Predominant hosting of $\mathrm{Pb}$ (II) was observed on the DA-host at the neutral $\mathrm{pH}$ region in the separation process. The evidence showed a first report on separation of heavy metal mixture by calix[4]resorcinarene. The equilibrium isotherms revealed that the adsorption of $\mathrm{Pb}$ (II), $\mathrm{Cu}$ (II), and $\mathrm{Ni}(\mathrm{II})$ onto N-host and DA-host adsorbents mainly fitted the Langmuir model. In addition, the adsorption of the metal ions on the calix[4]resorcinarene hosts was studied using ${ }^{1} \mathrm{H}-\mathrm{NMR}$ analysis. The obtained findings supported that the DA-host showed potential for use as an adsorbent for heavy metal $\mathrm{Pb}$ (II) because the diethylamino groups can coordinate with the heavy metal ions. This point might be important for further development of a new adsorption system for use with actual wastewater containing a mixture of heavy metals. There are also possibilities to apply the DA-host and N-host in specificity of heavy metal ion on bulk materials by some chemical treatments. Therefore, the progresses in these hosts are focused on several industrial applications in the field of wastewater treatment for elimination of such toxic ion from the wastes. The present results provide useful and variable information for further investigation of wastewater treatments.

Acknowledgments The authors deeply thank to the support of facilities from Department of Materials Science and Technology, Nagaoka University of Technology, Japan for this research.

\section{References}

Acemioglu B, Samil A, Alma HM, Gundogan R (2003) Copper(II) removal from aqueous solution by organosolve lignin and its recovery. J Appl Polym Sci 89:1537-1541

Aoyama Y, Tanaka Y, Sugahara S (1989) Molecular recognition of sugars via hydrogen-bonding interaction with synthetic polyhydroxymacrocycle. J Am Che Soc 111:5397-5404

Castillo M, Pina-Luis GM, Diaz-Garcia E, Rivero IA (2005) Solid phase organic synthesis of sensing sorbent materials for copper and lead recovery. J Braz Chem Soc 16:412-417

Faizal CKM, Kikuchi Y, Kobayashi T (2009) Molecular imprinting targeted for alpha-tocopherol by calix[4]resorcinarene derivative in membrane scaffold prepared by phase inversion. J Membrane Sci 334:110-116

Friberg L, Nordberg GF, Vouk B (1979) Introduction-general consideration and international perspectives. In: Nordberg GF, Fowler BA, Nordberg M, Friberg L (eds) Handbook on the toxicology of metals. Elsevier, Amsterdam

Gutsche CD (1989) Filling the baskets: complex formation with calixarenes. In: Gutsche CD (ed) calixarenes. The Royal Society of Chemistry, Cambridge

Izatt RM, Lamb JD, Hawkins RT, Brown PR, Izatt SR, Christensen JJ (1983) Selective $\mathrm{M}^{+}-\mathrm{H}^{+}$coupled transport of cations through a liquid membrane by macrocyclic calixarene ligands. J Am Chem Soc 105:1782-1785

Izatt SR, Hawkins RT, Christensen JJ, Izatt RM (1985) Cation transport from multiple alkali mixture using a liquid membrane system containing a sereis of calixarene carriers. J Am Chem Soc 107:63-66

Jain VK, Kanaiya PH (2011) Chemistry of calix[4]resorcinarenes. Russ Chem R 80(1):75-102

Johnson PD, Watson MA, Brown J, Jefcoat IA (2002) Peanut hull pellets as a single use sorbent for the capture of $\mathrm{Cu}$ (II) from wastewater. Waste Manage 22:471-480

Jumina Sarjono RE, Paramitha B, Hendanyani I, Siswanty D, Santosa SJ, Anwar C, Sastrohamidjojo H, Ohto K, Oshima T (2007) Adsorption characteristic of $\mathrm{Pb}$ (II) and $\mathrm{Cr}$ (III) onto c-4-methoxyphenylcalix[4]resorcinarene in batch and fixed bed column system. J Chin Chem Soc-Taip 54:1167-1178

Karthikeyan T, Rajgopal S, Miranda LR (2005) Chromium (VI) adsorption from aqueous solution by Hevea brasilinesis saw dust activated carbon. J Hazard Mater B124:192-199

Knyazeva IR, Sadykova YM, Burilov AR, Pudovik MA, Konovalov AI (2009) Mannich reaction in the calix[4]resorcinarenes series containing organophosphorus fragments on the lower molecule rim. Zh Obshch Khim 79(11):1930-1931

Ma BQ, Zhang Y, Coppens P (2001) The chair conformation of c-methylcalix[4]resorcinarene in a novel, stepped, supramolecular framework. Cryst Eng Comm 20:1-3

Minhas FT, Memon S, Banger MI (2010) Transport of $\mathrm{Hg}(\mathrm{II})$ through bulk liquid membrane containing calix[4]arene thioalkyl derivative as a carrier. Desalination 262:215-220

Ngah WSW, Hanafiah MAKM (2008) Adsorption of copper on rubber (Heavea bransiliensis) leaf powder: kinetic, equilibrium and thermodynamic studies. Biochem Eng J 39:521-530

Osu Charles I, Odoemelam SA (2010) Studies on adsorbent dossage, particle sizes and $\mathrm{pH}$ constraints on biosorption of $\mathrm{Pb}(\mathrm{II})$ and $\mathrm{Cd}$ (II) ions from aqueous solution using modified and unmodified Crasstrotrea gasar (bivalve) biomass. Int Arch Appl Sci Tech 1(1):62-68 
Panida S, Pisit C (2010) Equlibrium isotherm, thermodynamic and kinetic studies of lead adsorption onto pineapple and paper waste sludges. Int J Energ Environ 3(4):88-98

Rengaraj S, Yeon KH, Moon SH (2001) Removal of chromium from water and wastewater by ion exchange resins. J Hazard Mater $87: 273-287$
Turshatov AA, Melnikova YD, Semchikov IS, Ryzhkina TN, Pashirova D, Mobiu S, Zaitsev Y (2004) Interaction of monolayers of calix[4]resorcinarene derivatives with copper ions in the aqueous subphase. Colloid Surface A 240:101-106 